\title{
Author Correction: Spiraling pathways of global deep waters to the surface of the Southern Ocean
}

\author{
Veronica Tamsitt (10 1, Henri F. Drake (1) 2,6, Adele K. Morrison"2, ${ }^{2}$, Lynne D. Talley (1) ${ }^{1}$, Carolina O. Dufour ${ }^{2}$, \\ Alison R. Gray (1) ${ }^{2}$, Stephen M. Griffies ${ }^{3}$, Matthew R. Mazloff ${ }^{1}$, Jorge L. Sarmiento ${ }^{2}$, Jinbo Wang ${ }^{4}$ \& \\ Wilbert Weijer ${ }^{5}$
}

Nature Communications 8:172 https:/doi.org/10.1038/s41467-017-00197-0; Article published online: 2 August 2017

The original version of this Article contained errors in Fig. 6. In panel a, the grey highlights obscured the curves for CESM, CM2.6 and SOSE, and the labels indicating SWIR, KP, MR, PAR, and DP were inadvertently omitted. These have now been corrected in both the PDF and HTML versions of the Article.

Published online: 15 January 2018

\begin{abstract}
(c) Open Access This article is licensed under a Creative Commons Attribution 4.0 International License, which permits use, sharing, adaptation, distribution and reproduction in any medium or format, as long as you give appropriate credit to the original author(s) and the source, provide a link to the Creative Commons license, and indicate if changes were made. The images or other third party material in this article are included in the article's Creative Commons license, unless indicated otherwise in a credit line to the material. If material is not included in the article's Creative Commons license and your intended use is not permitted by statutory regulation or exceeds the permitted use, you will need to obtain permission directly from the copyright holder. To view a copy of this license, visit http://creativecommons.org/licenses/by/4.0/.
\end{abstract}

(C) The Author(s) 2018

\footnotetext{
${ }^{1}$ Scripps Institution of Oceanography, La Jolla, CA 92093, USA. ${ }^{2}$ Princeton University, Princeton, NJ 08544, USA. ${ }^{3}$ Geophysical Fluid Dynamics Laboratory, Princeton, NJ 08540, USA. ${ }^{4}$ Jet Propulsion Laboratory, California Institute of Technology, Pasadena, CA 91109, USA. ${ }^{5}$ Los Alamos National Laboratory, Los Alamos, NM 87545, USA. ${ }^{6}$ Present address: Massachusetts Institute of Technology and Woods Hole Oceanographic Institution Joint Program in Oceanography, Cambridge, MA, USA. ${ }^{7}$ Present address: Australian National University, Canberra, ACT 2602, Australia Correspondence and requests for materials should be addressed to V.T. (email: vtamsitt@ucsd.edu)
} 